\title{
Highly Efficient Red Phosphorescent OLEDs Based on Ir(III) Complexes with Fluorine-substituted Benzoylphenylpyridine Ligand
}

\author{
Hyun Ju Kang, Kum Hee Lee, Suk Jae Lee, ${ }^{\dagger}$ Ji Hyun Seo, ${ }^{\dagger}$ Young Kwan Kim, ${ }^{\dagger, *}$ and Seung Soo Yoon ${ }^{*}$
}

\author{
Department of Chemistry, Sungkyunkwan University, Suwon, Gyunggi-do 440-746, Korea. *E-mail: ssyoon@skku.edu \\ †Department of Information Display, Hongik University, Seoul 121-791, Korea. *E-mail: kimyk@wow.hongik.ac.kr \\ Received September 30, 2010, Accepted October 18, 2010
}

\begin{abstract}
Four orange-red phosphorescent Ir(III) complexes were designed and synthesized based on the benzoylphenylpyridine ligand with a fluorine substituent. Multilayered OLEDs with the device structure, ITO/2-TNATA/NPB/CBP : 8\% Ir(III) complexes/BCP/Liq/Al, were fabricated using these complexes as dopant materials. All the devices exhibited orange-red electroluminescence and their electroluminescent properties were quite sensitive to the structural features of the dopants in the emitting layers. Among these, the maximum luminance $\left(14700 \mathrm{~cd} / \mathrm{m}^{2}\right.$ at $\left.14.0 \mathrm{~V}\right)$ was observed in the device containing $\operatorname{Ir}(\mathrm{III})$ complex 1 as the dopant. In addition, its luminous, power and quantum efficiency were $11.7 \mathrm{~cd} / \mathrm{A}, 3.88$ $\mathrm{lm} / \mathrm{W}$ and $9.58 \%$ at $20 \mathrm{~mA} / \mathrm{cm}^{2}$, respectively. The peak wavelength of electroluminescence was $606 \mathrm{~nm}$ with CIE coordinates of $(0.61,0.38)$ at $12.0 \mathrm{~V}$. The device also showed stable color chromaticity with various voltages.
\end{abstract}

Key Words: Fluorine, Phosphorescent OLEDs, Ir(III) complex, 5-Benzoyl-2-phenylpyridine ligand

\section{Introduction}

Phosphorescent organic light-emitting diodes (OLEDs) are of great interest because both single and triplet excitons can be harvested for light emission. ${ }^{1-3}$ In addition, it is possible to increase their internal quantum efficiency to $100 \%$, corresponding to an external quantum efficiency of $>20 \%{ }^{4,5}$ These devices employ phosphorescent heavy metal complexes as the emitting materials that emit in the triplet metal-to-ligand charge transfer $\left({ }^{3}\right.$ MLCT) state. ${ }^{6,7} \mathrm{Ir}(\mathrm{III})$ complexes are the most popular electrophosphorescent emitting materials owing to their high efficiency and facile color tuning compared. ${ }^{8-10}$ Recently, a variety of $\operatorname{Ir}(\mathrm{III})$ complexes have been developed as electrophosphorescent emitters. ${ }^{11-13}$ Among those are Ir(III) complexes based on the carbonylated phenyl-pyridine ligands. ${ }^{14,15}$ For example, two orange-red emitters based on carbonylated phenyl-pyridine derivative-Ir(III) complexes, (Acppy) $)_{2} \mathbf{I r}$ (acac), and (Ibppy) $)_{2} \mathbf{I r}$ (acac) in OLEDs with high luminous efficiency and brightness (reach to $32.0 \mathrm{~cd} / \mathrm{A}$ and $20460 \mathrm{~cd} / \mathrm{m}^{2}$ ) were reported. ${ }^{16}$ (Bzppy) Ir(acac) (Fig. 1.) has been used to fabricate WOLEDs with a power efficiency of $28.7 \mathrm{~lm} / \mathrm{W}$ corresponding to an EQE value of $13.1 \%{ }^{17}$ In these $\mathrm{Ir}$ (III) complexes, the carbonyl group on the ligands was introduced as an electron-withdrawing groups to tune the band gap of the Ir(III) complex by lowering the HOMO and LUMO energy levels of the ligands. In addition, the electronwithdrawing carbonyl groups would enhance the electron mobility and improve the charge balance in the emitting layers of the devices, which is a key factor affecting the OLED device efficiency. However, their EL performance, such as EL efficiency and color purity, require improvement.

Recently, researchers from Dupont de Nemours and Co. synthesized and characterized a series of Ir(III) complexes with fluorinated 2-arylpyridines, and showed that the emissive colors of the materials can be finely tuned through systematic control of the nature and position of the ligands. ${ }^{18}$ In addition, fluorinated substituents in the aromatic ligand result in reduced luminance

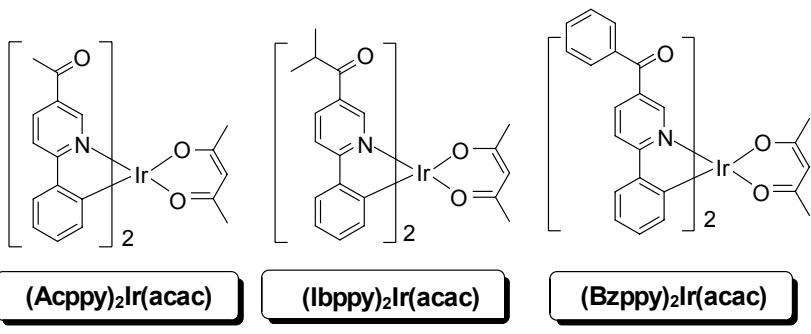

Figure 1. Structures of the Ir(III) complexes (Acppy) $)_{2} \operatorname{Ir}(\mathbf{a c a c})$, (Ibppy) $\operatorname{Ir}(\mathbf{a c a c})$, and (Bzppy) $\operatorname{Ir}$ (acac).

quenching due to the altered molecular packing and low $\mathrm{C}-\mathrm{F}$ vibrational frequency, which can lead to improved EL performance of the devices using them as emitting materials. ${ }^{19}$ These results motivated us to carry out a systematic study to improve the EL performance of the Ir(III) complexes based on the benzoyphenyl pyridine ligand with fluorine substituents. ${ }^{20}$

In this study, a series of red-phosphorescent Ir(III) complexes 1-4 based on fluorine-substituted benzoylphenylpyridine ligands were synthesized, and their electrophosphorescent properties were examined. Multilayered organic light-emitting diodes (OLEDs) were fabricated using the complexes as a dopant and their electroluminescent properties were assessed. Fluorine groups were introduced to the ligands as an electron-withdrawing group to tune the band gap of the Ir(III) complexes. Also, these modifications on the ligands would lead to the reduced luminance quenching due to the altered molecular packing and low C-F vibrational frequency and thus improve the EL efficiencies of devices using Ir(III) complexes 1-4 as dopants.

\section{Experiment}

Materials and measurements. Phenylboronic acid, 2,5-dibromopyridine, and $N, N$-dimethylbenzamide were used as received from Aldrich or TCI. 5-Benzoyl-2-bromopyridine ${ }^{21}$ and 2-(4- 
bromophenyl)pyridine (5) ${ }^{22}$ were synthesized as previously reported. The solvents were dried using standard procedures. All reagents were used as received from commercial sources, unless otherwise stated. All reactions were performed under $\mathrm{N}_{2}$ atmosphere. ${ }^{1} \mathrm{H}$ - and ${ }^{13} \mathrm{C}-\mathrm{NMR}$ were obtained using a Varian (Unity Inova $300 \mathrm{Nb}$ ) or Varian (Unity Inova 500NB) spectrometer at $300 \mathrm{MHz}$ and $500 \mathrm{MHz}$, respectively. FT-IR spectra were recorded using a Thermo Nicolet Avatar 320 FT-IR spectrometer. Low- and high-resolution mass spectra were recorded using a Jeol JMS-AX505WA spectrometer in FAB mode or a Jeol JMS600 spectrometer in EI mode.

Synthesis of L1: Compound 5 (1.50 g, $6.41 \mathrm{mmol})$ was charged into a flask, evacuated, and kept under argon. Anhydrous THF $(20.0 \mathrm{~mL})$ was added from a syringe under stirring and the solution was cooled to $-78{ }^{\circ} \mathrm{C}$ in a dry ice/acetone bath. Then, $n$-BuLi (1.6 M in hexane, $6.00 \mathrm{~mL}, 9.61 \mathrm{mmol}$ ) was added dropwise from a syringe within $10 \mathrm{~min}$. The reaction mixture was stirred for 35 min under continuous cooling, then 4-fluoro- $\mathrm{N}, \mathrm{N}$ dimethylbenzamide $(1.61 \mathrm{~g}, 9.61 \mathrm{mmol})$ in anhydrous THF $(25.0 \mathrm{~mL})$ was added drop-wise within $5 \mathrm{~min}$. The temperature $\left(-78^{\circ} \mathrm{C}\right)$ was maintained further for $1 \mathrm{hr}$. Upon completion, the reaction was quenched with saturated ammonium chloride and allowed to warm to room temperature. The mixture was extracted with diethyl ether, dried over sodium sulfate, filtered, and concentrated. After purification by chromatography on silica gel with 1:10 ethyl acetate:hexane as eluent, the product was a white solid with an isolated yield of $83 \%$. ${ }^{1} \mathrm{H}$ NMR $(300$ $\left.\mathrm{MHz}, \mathrm{CDCl}_{3}\right) \delta 9.05(\mathrm{dd}, J=0.9,2.3 \mathrm{~Hz}, 1 \mathrm{H}), 8.19(\mathrm{dd}, J=2.3$, $8.3 \mathrm{~Hz}, 1 \mathrm{H}), 8.11-8.08(\mathrm{~m}, 2 \mathrm{H}), 7.91(\mathrm{dd}, J=5.4,9.0 \mathrm{~Hz}, 2 \mathrm{H})$, 7.89 (dd, $J=0.9,8.3 \mathrm{~Hz}, 1 \mathrm{H}), 7.55-7.49(\mathrm{~m}, 3 \mathrm{H}), 7.21$ (t, $J=8.6$ $\mathrm{Hz}, 2 \mathrm{H}) .{ }^{13} \mathrm{C} \mathrm{NMR}\left(125 \mathrm{MHz}, \mathrm{CDCl}_{3}\right) \delta 193.4,165.9$ (d, $J=255$ $\mathrm{Hz}), 160.7,151.3,138.4(\mathrm{~d}, J=6.1 \mathrm{~Hz}), 133.6(\mathrm{~d}, J=3.0 \mathrm{~Hz})$, $132.9,132.8,131.4,130.3,129.2,127.6,120.2,116.1(\mathrm{~d}, J=$ $21.9 \mathrm{~Hz})$. IR (KBr) $v=1640,1594,1152,1098,1071,1021$, $852,751,734,690 \mathrm{~cm}^{-1}$. EI-MS $(\mathrm{m} / \mathrm{z}) 277\left[\mathrm{M}^{+}\right] \mathrm{HRMS}^{-E I^{+}}$calcd for $\mathrm{C}_{18} \mathrm{H}_{12} \mathrm{NOF}$ : 277.0903. found: 277.0901 .

General procedure for the suzuki cross-coupling reaction. 5-Benzoyl-2-bromopyridine $(1.0 \mathrm{~mol})$ and the corresponding phenylboronic acid derivatives (1.2 mol), $\mathrm{Pd}\left(\mathrm{PPh}_{3}\right)_{4}(0.04 \mathrm{~mol})$, aqueous $2 \mathrm{M} \mathrm{Na}_{2} \mathrm{CO}_{3}(10.0 \mathrm{~mol})$, ethanol, and toluene were mixed in a flask. The mixture was refluxed for $5 \mathrm{~h}$. After the reaction had finished, the reaction mixture was extracted with ethyl acetate and washed with water. The combined organic layer was dried with anhydrous $\mathrm{MgSO}_{4}$ and evaporated to dryness. The crude product was further purified by silica gel column chromatography with 2:1 dichloromethane:hexane as eluent.

Synthesis of L2: Yield 91\%. ${ }^{1} \mathrm{H}$ NMR $\left(300 \mathrm{MHz}, \mathrm{CDCl}_{3}\right) \delta$ 9.05 (d, $J=2.2 \mathrm{~Hz}, 1 \mathrm{H}), 8.21$ (dd, $J=2.2,8.3 \mathrm{~Hz}, 1 \mathrm{H}), 8.09$ (dd, $J=5.3,8.9 \mathrm{~Hz}, 2 \mathrm{H}), 7.87-7.82(\mathrm{~m}, 3 \mathrm{H}), 7.67-7.62(\mathrm{~m}, 1 \mathrm{H}), 7.56-$ $7.52(\mathrm{~m}, 2 \mathrm{H}), 7.20(\mathrm{t}, J=8.7 \mathrm{~Hz}, 2 \mathrm{H}) .{ }^{13} \mathrm{C} \mathrm{NMR}(125 \mathrm{MHz}$, $\left.\mathrm{CDCl}_{3}\right) \delta 194.9,164.4(\mathrm{~d}, J=250.5 \mathrm{~Hz}), 157.5,151.5,138.6$, $137.2,134.0(\mathrm{~d}, J=3.0 \mathrm{~Hz}), 133.3,131.4,130.2,129.5(\mathrm{~d}, J=8.5$ $\mathrm{Hz}), 128.9,119.8,116.2(\mathrm{~d}, J=21.7 \mathrm{~Hz})$. IR (KBr) $v=3068$, 1644, 1586, 1507, 1317, 1288, 1233, 1160, 923, 837, 798, 706, $673 \mathrm{~cm}^{-1}$. EI-MS $(\mathrm{m} / z) 277\left[\mathrm{M}^{+}\right]$HRMS-EI ${ }^{+}$calcd for $\mathrm{C}_{18} \mathrm{H}_{12}-$ FON: 277.0903. found : 277.0904.

Synthesis of L3: Yield 92\%. ${ }^{1} \mathrm{H}$ NMR $\left(300 \mathrm{MHz}, \mathrm{CDCl}_{3}\right) \delta$ 9.09 (dd, $J=0.8,2.2 \mathrm{~Hz}, 1 \mathrm{H}), 8.21-8.11(\mathrm{~m}, 2 \mathrm{H}), 7.94-7.91$ (m,
1H), 7.87-7.84 (m, 2H), 7.67-7.63 (m, 1H), 7.56-7.51 (m, 2H), 7.08-7.02 (m, 1H), 6.99-6.92 (m, 1H). ${ }^{13} \mathrm{C}$ NMR (125 MHz, $\left.\mathrm{CDCl}_{3}\right) \delta 194.8,164.1(\mathrm{dd}, J=12.3 \mathrm{~Hz}, 254.7 \mathrm{~Hz}), 161.2(\mathrm{dd}$, $J=12.0,253.9 \mathrm{~Hz}), 155.67(\mathrm{~d}, J=2.0 \mathrm{~Hz}), 151.3,138.2,137.1$, $133.4,132,7$ (dd, $J=4.1,9.9 \mathrm{~Hz}), 131.7,130.2,128.9,123.8$ (d, $J=10.7 \mathrm{~Hz}), 123.0(\mathrm{dd}, J=3.7 \mathrm{~Hz}, 11.2 \mathrm{~Hz}), 112.5$ (dd, $J=3.6$, $21.2 \mathrm{~Hz}), 104.9(\mathrm{t}, J=26.2 \mathrm{~Hz})$. IR (KBr) $v=3068,3034,1662$, 1592, 1507, 1469, 1430, 1311, 1280, 1146, 1111, 960, 927, 855, $771,710,676 \mathrm{~cm}^{-1}$. EI-MS ( $\left.\mathrm{m} / \mathrm{z}\right) 295\left[\mathrm{M}^{+}\right]$HRMS-EI ${ }^{+}$calcd for $\mathrm{C}_{18} \mathrm{H}_{11} \mathrm{~F}_{2} \mathrm{NO}: 295.0809$. found: 295.0810.

Synthesis of L4: Yield 97\%. ${ }^{1} \mathrm{H}$ NMR $\left(300 \mathrm{MHz} \mathrm{CDCl}_{3}\right) \delta$ 9.07 (dd, $J=0.9,2.2 \mathrm{~Hz}, 1 \mathrm{H}), 8.23$ (dd, $J=2.2,8.2 \mathrm{~Hz}, 1 \mathrm{H}), 7.85$ $(\mathrm{dd}, J=1.4,8.3 \mathrm{~Hz}, 2 \mathrm{H}), 7.83(\mathrm{dd}, J=0.9,8.2 \mathrm{~Hz}, 1 \mathrm{H}), 7.69-$ $7.61(\mathrm{~m}, 3 \mathrm{H}), 7.57-7.51(\mathrm{~m}, 2 \mathrm{H}), 6.92(\mathrm{tt}, J=2.3,6.3 \mathrm{~Hz}, 1 \mathrm{H})$. ${ }^{13} \mathrm{C}$ NMR (125 MHz, $\mathrm{CDCl}_{3}$ ) $\delta 194.6,163.7$ (dd, $J=12.7,248.7$ $\mathrm{Hz}), 157.8$ (t, $J=2.9 \mathrm{~Hz}), 151.4,141.7,138.7,136.9,133.5$, $132.5,130.2,128.9,120.2,110.5(\mathrm{dd}, J=6.5 \mathrm{~Hz}, 20.3 \mathrm{~Hz}), 105.5$ $(\mathrm{t}, J=25.4 \mathrm{~Hz})$. IR (KBr) $v=3085,1657,1620,1592,1444$, $1339,1283,1118,987,849,707 \mathrm{~cm}^{-1}$. EI-MS $(\mathrm{m} / z) 295\left[\mathrm{M}^{+}\right]$ HRMS-EI ${ }^{+}$calcd for $\mathrm{C}_{18} \mathrm{H}_{11} \mathrm{~F}_{2} \mathrm{NO}$ : 295.0809. found: 295.0806 .

General procedure for the synthesis of Ir(III) complex 1. L1 $(0.74 \mathrm{~g}, 2.2 \mathrm{mmol})$ was dissolved in 2-ethoxyethanol $(9 \mathrm{~mL})$ in a $30 \mathrm{~mL}$ round-bottom flask. $\mathrm{IrCl}_{3} \cdot 3 \mathrm{H}_{2} \mathrm{O}(0.30 \mathrm{~g}, 1.0 \mathrm{mmol})$ and water $(3 \mathrm{~mL})$ were then added to the flask. The mixture was stirred under nitrogen at $120^{\circ} \mathrm{C}$ for $24 \mathrm{~h}$ and cooled to room temperature. The precipitate formed in the mixture was collected and washed with methanol, hexane and dried in vacuum to give the corresponding cyclometalated $\operatorname{Ir}(\mathrm{III})-\mu$-chloro-bridge dimer. In a $20 \mathrm{~mL}$ flask, the dimer complex, acetylacetone $(1.5 \mathrm{~mL}, 1.5$ $\mathrm{mmol})$ and $\mathrm{Na}_{2} \mathrm{CO}_{3}(0.32 \mathrm{~g}, 3.0 \mathrm{mmol})$ were mixed with 2-ethoxyethanol $(10 \mathrm{~mL})$ and mixture was heated at $100{ }^{\circ} \mathrm{C}$ for $6 \mathrm{~h}$. After cooling to room temperature, the precipitation solid was collected by filtration, and washed with ethanol and hexane. The residue was dissolved in dichloromethane and the solid was filtered off. The solution was concentrated in vacuo and the residue was purified on a silica gel column using dichloromethane and hexane as eluent. The product was obtained after recrystallization from dichloromethane/ethanol. Similar procedures were also employed for the synthesis of other Ir(III) complexes. The yields and spectral data of all Ir(III) complexes are as follows.

Complex 1: Yield 31\%. ${ }^{1} \mathrm{H}$ NMR (300 MHz, $\left.\mathrm{CDCl}_{3}\right) \delta 8.86$ $(\mathrm{d}, J=2.0 \mathrm{~Hz}, 2 \mathrm{H}), 8.26(\mathrm{dd}, J=2.0,8.5 \mathrm{~Hz}, 2 \mathrm{H}), 7.99$ (d, $J=8.6$ $\mathrm{Hz}, 2 \mathrm{H}), 7.86(\mathrm{dd}, J=5.4,8.7 \mathrm{~Hz}, 4 \mathrm{H}), 7.64(\mathrm{dd}, J=1.1,7.8 \mathrm{~Hz}$, 2H), $7.19(\mathrm{t}, J=8.5 \mathrm{~Hz}, 4 \mathrm{H}), 6.82(\mathrm{td}, J=1.1,7.5 \mathrm{~Hz}, 2 \mathrm{H}), 6.75$ $(\mathrm{td}, J=1.3,7.4 \mathrm{~Hz}, 2 \mathrm{H}), 6.29(\mathrm{dd}, J=1.1,7.5 \mathrm{~Hz}, 2 \mathrm{H}), 5.29(\mathrm{~s}$, 1H), $1.59(\mathrm{~s}, 6 \mathrm{H}) .{ }^{13} \mathrm{C}$ NMR $\left(125 \mathrm{MHz}, \mathrm{CDCl}_{3}\right) \delta 191.3,185.3$, $172.5,165.8(\mathrm{~d}, J=255 \mathrm{~Hz}), 150.7,150.4,143.5,138.7,133.6$, $133.4(\mathrm{~d}, J=3.0 \mathrm{~Hz}), 132.7(\mathrm{~d}, J=9.2 \mathrm{~Hz}), 130.9,130.5,125.9$, $121.6,118.4,116.1(\mathrm{~d}, J=22.0 \mathrm{~Hz}), 100.8,28.8 . \mathrm{IR}(\mathrm{KBr}) v=$ 3054, 1659, 1598, 1578, 1512, 1487, 1400, 1283, 1264, 1232, $1156,909,755,733 \mathrm{~cm}^{-1}$. FAB-MS $(\mathrm{m} / \mathrm{z}) 844\left[\mathrm{M}^{+}\right]$HRMS$\mathrm{FAB}^{+}$calcd for $\mathrm{C}_{41} \mathrm{H}_{29} \mathrm{IrF}_{2} \mathrm{~N}_{2} \mathrm{O}_{4}$ : 844.1725. found: 844.1733.

Complex 2: Yield 30\%. ${ }^{1} \mathrm{H}$ NMR $\left(300 \mathrm{MHz}, \mathrm{CDCl}_{3}\right) \delta 8.81$ $(\mathrm{d}, J=2.0 \mathrm{~Hz}, 2 \mathrm{H}), 8.30$ (dd, $J=2.0,8.5 \mathrm{~Hz}, 2 \mathrm{H}), 7.92$ (d, $J=8.6$ $\mathrm{Hz}, 2 \mathrm{H}), 7.80$ (d, $J=7.0 \mathrm{~Hz}, 4 \mathrm{H}), 7.67-7.60$ (m, 4H), 7.54-7.49 $(\mathrm{m}, 4 \mathrm{H}), 6.61(\mathrm{td}, J=2.5,8.7 \mathrm{~Hz}, 2 \mathrm{H}), 5.91(\mathrm{dd}, J=2.5,9.5 \mathrm{~Hz}$, $2 \mathrm{H}), 5.28(\mathrm{~s}, 1 \mathrm{H}), 1.57(\mathrm{~s}, 6 \mathrm{H}) .{ }^{13} \mathrm{C} \mathrm{NMR}\left(125 \mathrm{MHz}, \mathrm{CDCl}_{3}\right) \delta$ 
$192.7,185.4,171.1,163.98(\mathrm{~d}, J=256.2 \mathrm{~Hz}), 153.1(\mathrm{~d}, J=6.7$ $\mathrm{Hz}), 150.9,139.8$ (d, $J=1.5 \mathrm{~Hz}), 139.1,137.0,133.1,130.47$, 130.0, 128.9, 127.8 (d, $J=9.8 \mathrm{~Hz}), 119.68(\mathrm{~d}, J=17.1 \mathrm{~Hz}), 118.4$, $109.4(\mathrm{~d}, J=23.7 \mathrm{~Hz}), 101.1,53.7,28.8 . \mathrm{IR}(\mathrm{KBr}) v=3059$, $1661,1597,1547,1515,1446,1397,1314,1285,1261,1187$, $949,910,849,788,765,730,669 \mathrm{~cm}^{-1}$. FAB-MS $(\mathrm{m} / \mathrm{z}) 844$ $\left[\mathrm{M}^{+}\right]$HRMS-FAB ${ }^{+}$calcd for $\mathrm{C}_{41} \mathrm{H}_{29} \mathrm{~F}_{2} \mathrm{IrN}_{2} \mathrm{O}_{4}$ 844.1725: found, 844.1711 .

Complex 3: Yield 37\%. ${ }^{1} \mathrm{H}$ NMR (300 MHz, $\left.\mathrm{CDCl}_{3}\right) \delta 8.81$ $(\mathrm{d}, J=1.9 \mathrm{~Hz}, 2 \mathrm{H}), 8.41-8.31(\mathrm{~m}, 4 \mathrm{H}), 7.82-7.79(\mathrm{~m}, 4 \mathrm{H}), 7.64$ $(\mathrm{t}, J=7.4 \mathrm{~Hz}, 2 \mathrm{H}), 7.53(\mathrm{t}, J=7.6 \mathrm{~Hz}, 4 \mathrm{H}), 6.43-6.36(\mathrm{~m}, 2 \mathrm{H})$, $5.70(\mathrm{dd}, J=2.3,8.6 \mathrm{~Hz}, 2 \mathrm{H}), 5.31(\mathrm{~s}, 1 \mathrm{H}), 1.59(\mathrm{~s}, 6 \mathrm{H}) .{ }^{13} \mathrm{C}$ NMR $\left(125 \mathrm{MHz}, \mathrm{CD}_{2} \mathrm{Cl}_{2}\right) \delta 192.3,185.7,168.3(\mathrm{~d}, J=6.8 \mathrm{~Hz})$, $163.9(\mathrm{dd}, J=13.0,200.0 \mathrm{~Hz}), 161.9(\mathrm{dd}, J=12.9,203.0 \mathrm{~Hz})$, $153.5(\mathrm{~d}, J=7.3 \mathrm{~Hz}), 150.5,139.8,136.8,133.3,131.0,130.0$, $129.9,129.0,122.5(\mathrm{~d}, J=19.5 \mathrm{~Hz}), 115.7(\mathrm{dd}, J=2.7,16.8 \mathrm{~Hz})$, 101.1, 97.9 (t, $J=26.9 \mathrm{~Hz}), 28.4$. IR $(\mathrm{KBr}) v=3060,1663$, $1598,1573,1516,1485,1397,1380,1278,1104,989,850,833$, $716 \mathrm{~cm}^{-1}$. FAB-MS $(\mathrm{m} / z) 880\left[\mathrm{M}^{+}\right]$HRMS-FAB ${ }^{+}$calcd for $\mathrm{C}_{41} \mathrm{H}_{27} \mathrm{~F}_{4} \mathrm{IrN}_{2} \mathrm{O}_{4}$ 880.1536: found, 880.1532.

Complex 4: Yield 32\%. ${ }^{1} \mathrm{H}$ NMR (300 MHz, $\left.\mathrm{CDCl}_{3}\right) \delta 8.79$ $(\mathrm{d}, J=2.0 \mathrm{~Hz}, 2 \mathrm{H}), 8.29(\mathrm{dd}, J=2.0,8.5 \mathrm{~Hz}, 2 \mathrm{H}), 7.89(\mathrm{~d}, J=8.6$ $\mathrm{Hz}, 2 \mathrm{H}), 7.81-7.78(\mathrm{~m}, 4 \mathrm{H}), 7.63-7.60(\mathrm{~m}, 2 \mathrm{H}), 7.54-7.49(\mathrm{~m}$, $4 \mathrm{H}), 7.30(\mathrm{dd}, J=2.3,9.2 \mathrm{~Hz}, 2 \mathrm{H}), 6.29(\mathrm{td}, J=2.3,9.2 \mathrm{~Hz}, 2 \mathrm{H})$, $5.29(\mathrm{~s}, 1 \mathrm{H}), 1.54(\mathrm{~s}, 6 \mathrm{H}) .{ }^{13} \mathrm{C} \mathrm{NMR}\left(125 \mathrm{MHz}, \mathrm{CD}_{2} \mathrm{Cl}_{2}\right) \delta 192.5$, 185.3, 170.7 (d, $J=3.4 \mathrm{~Hz}), 169.5$ (dd, $J=11.1,238.9 \mathrm{~Hz}), 159.7$ (dd, $J=12.1,239.1 \mathrm{~Hz}), 151.1,148.0(\mathrm{dd}, J=8.9 \mathrm{~Hz}, 18.1 \mathrm{~Hz})$, 139.0, 136.9, 133.3, 131.5, 129.9, 128.9, $122.0(\mathrm{dd}, J=2.7,37.4$ $\mathrm{Hz}), 119.2,108.2$ (dd, $J=3.7,21.5 \mathrm{~Hz}), 105.3$ (dd, $J=24.6,31.8$ $\mathrm{Hz}), 101.2,28.3$. IR (KBr) $v=3065,1662,1601,1572,1516$, $1422,1396,1322,1288,1268,1090,992,909,849,732,714$ $\mathrm{cm}^{-1}$. FAB-MS $(\mathrm{m} / \mathrm{z}) 880\left[\mathrm{M}^{+}\right]$HRMS-FAB ${ }^{+}$calcd for $\mathrm{C}_{41} \mathrm{H}_{27^{-}}$ $\mathrm{F}_{4} \mathrm{IrN}_{2} \mathrm{O}_{4}: 880.1536$. found: 880.1533.

Fabrication of OLEDs. OLEDs were fabricated using a red dopant in the emitting layers. High vacuum $\left(5 \times 10^{-7}\right.$ torr $)$ thermal deposition was used to place organic materials onto the surface of an indium thin oxide (ITO, $30 \Omega / \mathrm{sq}, 80 \mathrm{~nm}$ )-coated glass substrate. The ITO glass was cleaned with acetone, methanol, distilled water, and isopropyl alcohol. The organic materials and metal were deposited sequentially to from devices in the following configuration: ITO/4,4',4' '-tris( $N$-(naphtalen-2-yl)- $N$ phenyl-amino)triphenylamine $(60 \mathrm{~nm}) / 4,4$ '-bis(N-naphtylphenylamino)biphenyl (20 nm)/Ir(III) complexes ( $8 \%$ ) doped in 4,4'- $N, N^{\prime}$-dicarbazolebiphenyl (30 nm)/2,9-Dimethyl-4,7-diphenyl-1,10-phenanthroline (10 nm)/tris(8-hydroxyquinolinyl) aluminum(III) $(20 \mathrm{~nm}) / \mathrm{Liq}(2 \mathrm{~nm}) / \mathrm{Al}(100 \mathrm{~nm})$. The typical organic deposition rate was $0.1 \mathrm{~nm} / \mathrm{sec}$. Finally, $100 \mathrm{~nm}$ of Al was deposited as a cathode. The active area of the OLEDs was 0.09 $\mathrm{cm}^{2}$. After the fabrication, the current-voltage $(\mathrm{J}-\mathrm{V})$ characteristics of the OLEDs were measured with a source measure unit (Keithley 236). The luminance and CIE chromaticity coordinates of the fabricated devices were measured using a chromameter (MINOLTA CS-100A). Electroluminance was measured using an LS-50B. All measurements were performed in ambient conditions under DC voltage bias.

\section{Results and Discussion}

Scheme 1 outlines the structures and synthetic processes of the Ir(III) complexes (1-4). The ligands were synthesized using a Suzuki cross coupling reaction with moderate yield. The Ir(III) complexes were obtained by cyclometallation of the ligands
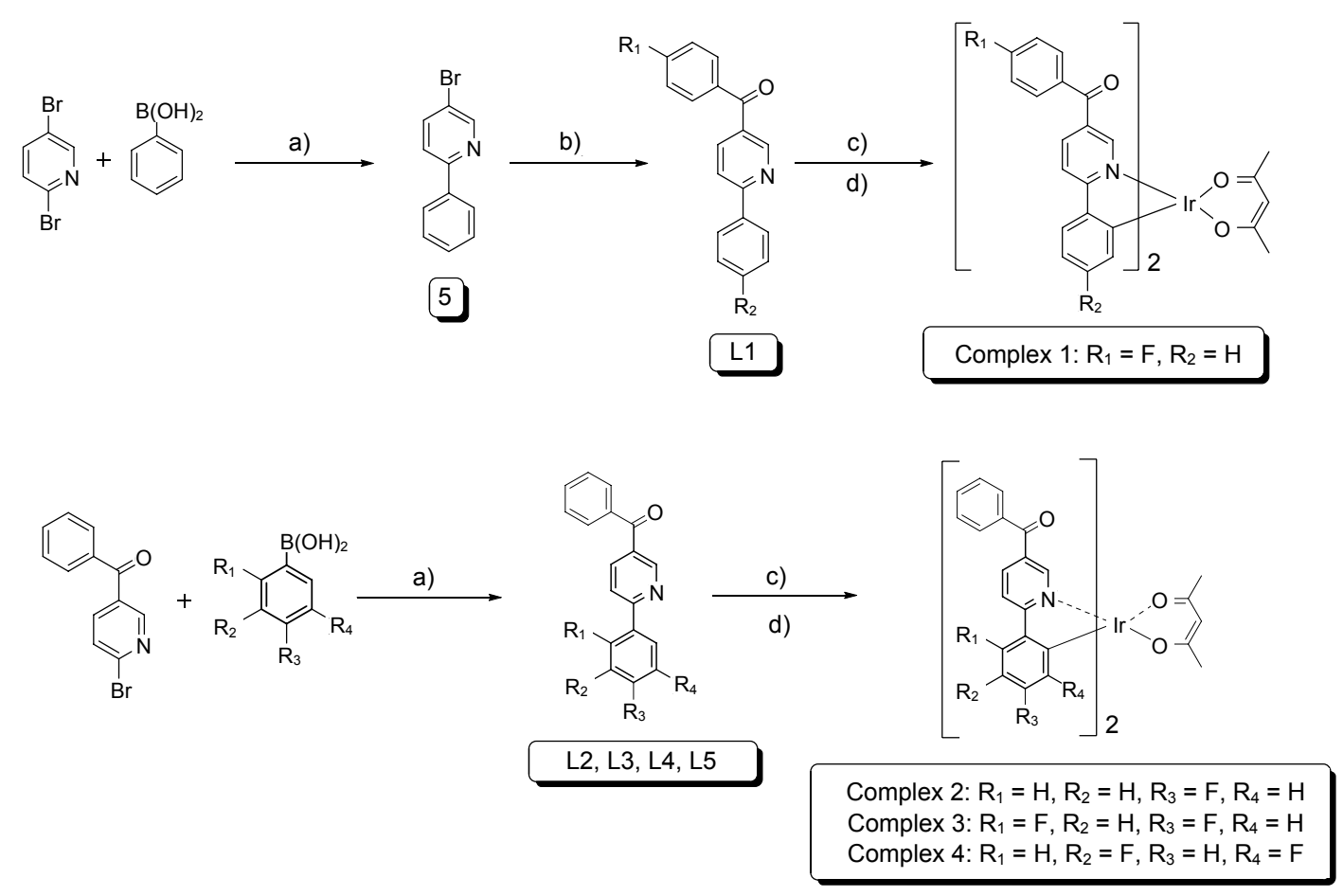

Scheme 1. Synthetic route to $\mathrm{Ir}(\mathrm{III})$ complexes 1-4. Conditions: (a) $\mathrm{Pd}\left(\mathrm{PPh}_{3}\right)_{4}, 2 \mathrm{M} \mathrm{Na}_{2} \mathrm{CO}_{3}, \mathrm{EtOH}$, toluene, $2 \mathrm{~h}$, reflux. (b) $n$-BuLi, 4-fluorine$\mathrm{N}, \mathrm{N}$-dimethylbenzamide, THF. (c) $\mathrm{IrCl}_{3} \cdot \mathrm{H}_{2} \mathrm{O}, \mathrm{H}_{2} \mathrm{O}, 2$-ethoxyethanol, $120{ }^{\circ} \mathrm{C}, 24 \mathrm{~h}$. (d) 2,4-pentanedione, $\mathrm{Na}_{2} \mathrm{CO}_{3}$, 2-ethoxyethanol, $100{ }^{\circ} \mathrm{C}, 6 \mathrm{~h}$. 
(a)

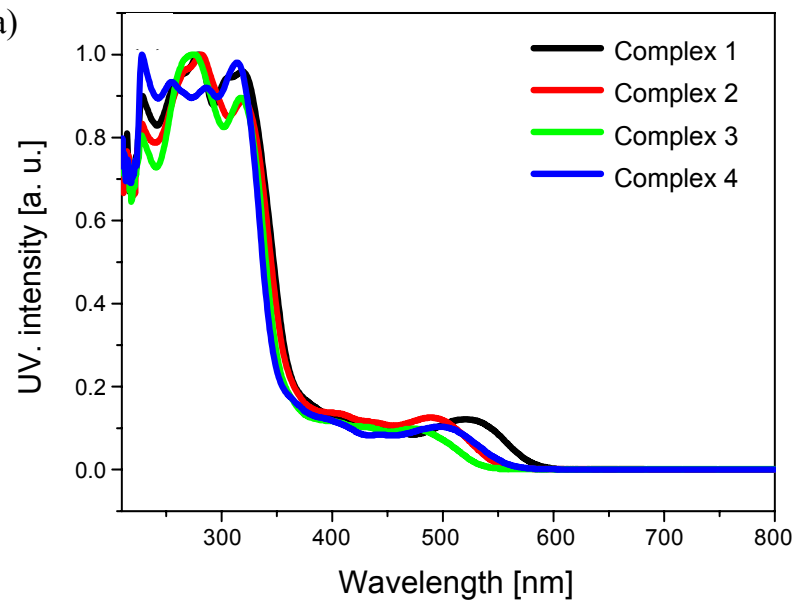

(b)

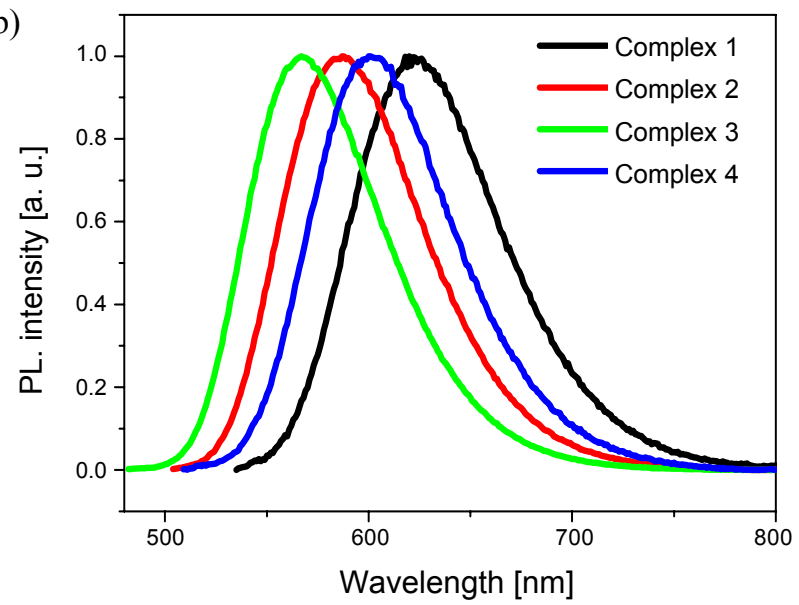

Figure 2. (a) The absorption, and (b) emission spectra of 1-4.

Table 1. Optical properties of the Ir(III) complexes.

\begin{tabular}{clcccc}
\hline Compound & \multicolumn{1}{c}{$\lambda_{\max }{ }^{a}[\mathrm{~nm}]$} & $\lambda_{\max }{ }^{b}[\mathrm{~nm}]$ & HOMO/LUMO $[\mathrm{eV}]$ & $\mathrm{E}_{\mathrm{g}}$ & $\Phi^{c}$ \\
\hline $\mathbf{1}$ & $318.5(5.90), 518.0(0.75)$ & 620 & $5.68 / 3.43$ & 2.25 & 0.36 \\
$\mathbf{2}$ & $281.5(6.20), 319.5(5.52), 487.5(0.80)$ & 587 & $5.86 / 3.45$ & 2.41 & 0.26 \\
$\mathbf{3}$ & $317.5(4.86), 424.5(0.56), 473.0(0.53)$, & 567 & $5.77 / 3.28$ & 2.49 & 0.36 \\
$\mathbf{4}$ & $286.0(6.34), 314.0(6.75), 442.5(0.59), 498.0(0.72)$ & 601 & $5.51 / 3.17$ & 2.34 & 0.28 \\
$\mathbf{( B z p p y}_{\mathbf{2}} \mathbf{I r}$ (acac) $^{d}$ & $289(4.31), 330(4.30), 523(0.20)$ & 619 & $5.28 / 3.06$ & 2.22 & 0.29 \\
\hline
\end{tabular}

${ }^{a}$ Maximum absorption and emission wavelength, measured in $\mathrm{CH}_{2} \mathrm{Cl}_{2}$ solution. ${ }^{b}$ Obtained from $\mathrm{AC}-2$ and absorption measurement. ${ }^{c}$ Using fac-[Ir(ppy) 3$]$ as a standard; $\lambda_{\mathrm{ex}}=400 \mathrm{~nm}\left(\Phi_{\mathrm{p}}=0.40\right.$ in $\left.\mathrm{CH}_{2} \mathrm{Cl}_{2}\right) .{ }^{d}$ Ref. 28 .

with $\mathrm{IrCl}_{3}$ and a subsequent reaction with acetylacetone. ${ }^{23}$ After conventional purification, such as column chromatography and recrystallization, these synthesized red-emitting materials (1-4) were purified further by train sublimation at a reduced pressure $\left(<10^{-3}\right.$ torr $)$ and characterized by ${ }^{1} \mathrm{H}$ - and ${ }^{13} \mathrm{C}$ NMR, infrared (IR), and low- and high-resolution mass spectrometry. High-pressure liquid chromatography (HPLC) analysis showed that the purity of the red-emitting materials (1-4) was at least $99.0 \%$.

Optical properties. Fig. 2 shows the absorption and emission spectra of the $\operatorname{Ir}(\mathrm{III})$ complexes (1-4), and their data is summarized in Table 1. The absorption spectra of Ir(III) complexes 1-4 below $360 \mathrm{~nm}$ were assigned to the spin-allowed ${ }^{1} \pi-\pi^{*}$ transition involving Bzppy (benzoylphenyl pyridine) ligands, and the band at approximately $400 \mathrm{~nm}$ to a spin-allowed metal charge transfer $\left({ }^{1}\right.$ MLCT) band. All the red phosphors showed strong absorption at $450-550 \mathrm{~nm}$, which was assigned to a spin-forbidden $\left({ }^{3} \mathrm{ML}-\right.$ CT) band. ${ }^{24-26}$ The maximum emission wavelength $\left(\lambda_{\max }\right)$ of 1-4 appeared at $620,587,567$, and $601 \mathrm{~nm}$, respectively. Compared to (Bzppy) $)_{2} \mathbf{I r}$ (acac) without fluorine substituents, the maximum emission wavelength of complex $\mathbf{2}$ with fluorine in the phenyl unit showed a blue-shift ( $c a .32 \mathrm{~nm}$ ). In addition, the maximum emission wavelength of complex 3 with a 2,4-positioned fluorine groups in the phenyl unit showed a blue-shift ( $c a .52 \mathrm{~nm}$ ) in the emission spectra. This suggests that fluorine substituents at the 2,4-position in the pyridine unit of the ligand reduce the HOMO energy levels and increase the energy band gaps of the Ir(III) complexes.

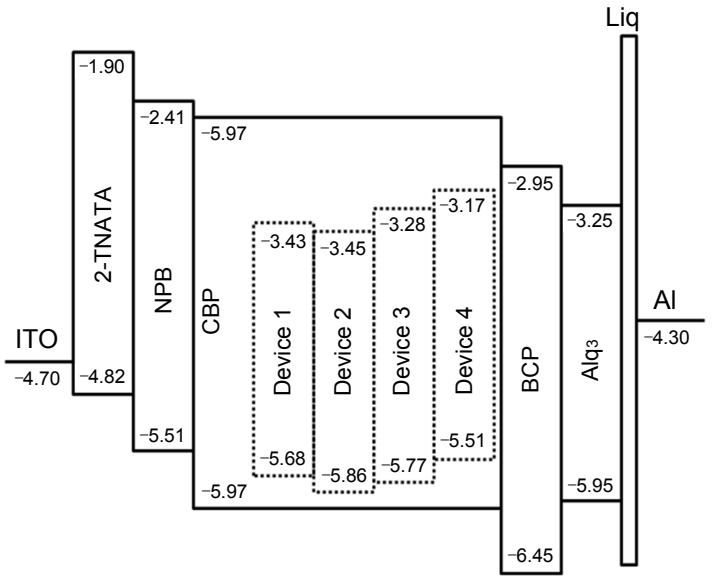

Figure 3. Energy-level diagrams of OLEDs.

The maximum emission wavelength of complex 1 with fluorine in the benzoyl unit was similar to that of (Bzppy) $)_{2} \operatorname{Ir}$ (acac) because fluorine substituents at the benzoyl unit of the ligand decrease the LUMO and HOMO energy levels. Interestingly, the maximum emission wavelength of complex $\mathbf{4}$ is significantly red-shifted compared to complex $\mathbf{3}$. In addition, the HOMO energy level of complex $\mathbf{3}$ with fluorine at the 2,4-position is lower than that of complex 4 with fluorine at the 3,5-position. This indicates that the energy levels differ according to the position of the fluorine. ${ }^{1,27}$ Their emission quantum yields were 0.36 , $0.26,0.36$ and 0.28 , respectively, as determined using $\operatorname{Ir}(\mathrm{ppy})_{3}$ 
Table 2. EL performance characteristics of the devices 1-4

\begin{tabular}{cccccccc}
\hline Device & $\lambda_{\max }{ }^{\mathrm{EL}}[\mathrm{nm}]$ & $\mathrm{V}_{\text {on }}{ }^{a}\left[\mathrm{~cd} / \mathrm{m}^{2}\right]$ & $\mathrm{L}^{b}\left[\mathrm{~cd} / \mathrm{m}^{2}\right]$ & $\mathrm{LE}^{c, d}[\mathrm{~cd} / \mathrm{A}]$ & $\mathrm{PE}^{c, d}[\mathrm{~lm} / \mathrm{W}]$ & $\mathrm{QE}^{c, d}[\%]$ & $\mathrm{CIE}^{e}(\mathrm{x}, \mathrm{y})$ \\
\hline $\mathbf{1}$ & 606 & 3.9 & 14700 & $15.6 / 11.7$ & $10.1 / 3.88$ & $10.5 / 9.58$ & $(0.61,0.39)$ \\
$\mathbf{3}$ & 571 & 3.6 & 34700 & $40.5 / 30.4$ & $29.9 / 10.1$ & $13.7 / 8.23$ & $(0.49,0.51)$ \\
$\mathbf{4}$ & 550 & 3.7 & 24400 & $30.3 / 20.9$ & $22.8 / 6.56$ & $6.61 / 4.52$ & $(0.42,0.57)$ \\
(Bzppy) $_{2} \mathbf{I r}(\mathbf{a c a c})^{f}$ & 585 & 4.0 & 16400 & $27.9 / 18.9$ & $21.9 / 5.56$ & $14.3 / 9.56$ & $(0.56,0.44)$ \\
& 594 & 4.0 & 24000 & $15.3 / 7.7$ & $5.93 / 1.18$ & $10.4 / 6.55$ & $(0.61,0.38)$ \\
\hline
\end{tabular}

${ }^{a}$ Turn-on voltage at $1 \mathrm{~cd} / \mathrm{m}^{2} .{ }^{b}$ Maximum luminance and current density. ${ }^{c}$ Maximum values. ${ }^{d}$ At $20 \mathrm{~mA} / \mathrm{cm}^{2} .{ }^{e}$ Commission Internationale d'Énclairage (CIE) coordinates at a $12.0 \mathrm{~V} .{ }^{f}$ Ref. 28.

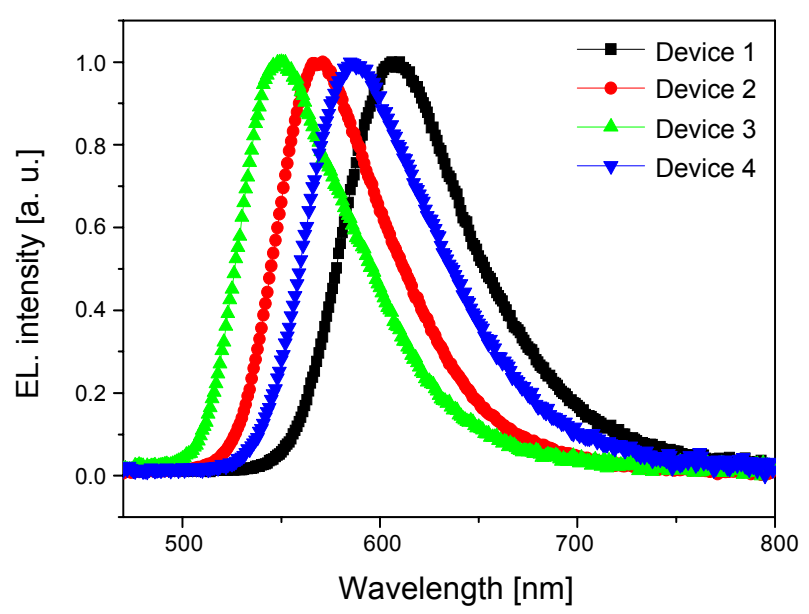

Figure 4. EL spectra of the devices 1-4.

(0.40) used as the reference. ${ }^{28}$ The respective HOMO energy levels of 1-4 were measured at $-5.68,-5.86,-5.77$ and $-5.51 \mathrm{eV}$ by low-energy photoelectron spectrometer (Riken-Keiki AC-2). The optical energy band gaps $\left(\mathrm{E}_{\mathrm{g}}\right)$ of $\mathbf{1 - 4}$ were $2.25-2.49 \mathrm{eV}$, as determined from the absorption spectra. The LUMO energy levels, which were calculated by subtracting the optical band gap energy from the HOMO levels, were $-3.43,-3.45,-3.28$ and $-3.17 \mathrm{eV}$, respectively.

Electroluminescence properties. Four devices 1-4 were fabricated with the $8 \% \operatorname{Ir}(\mathrm{III})$ complexes $\mathbf{1 - 4}$ as a dopant within the CBP host in the emitting layers using identical configurations. Table 2 lists the EL characteristics of devices 1-4. As shown in Fig. 4, devices 1-4 exhibited red-orange-yellow emission with maximum emission peaks between $550-606 \mathrm{~nm}$, which is quite sensitive to the position of the fluorine substituent in the ligand. The CIE coordinates of devices $\mathbf{1 - 4}$ were $(0.61,0.38),(0.49$, $0.51),(0.42,0.57)$ and $(0.56,0.44)$, respectively. This trend of the CIE coordinates of devices 1-4 is compatible with the PL spectra of $\operatorname{Ir}$ (III) complexes 1-4. The turn-on voltages of 3.6 - 4.0 $\mathrm{V}$ observed for such devices are generally $<4.0$, which is in line with the higher electron mobility of the carbonyl group. Figs. 5 and 6 show the current density-voltage-luminance $(J-V-L)$ characteristics, luminous efficiencies (LE), power efficiencies (PE), and external quantum efficiencies (EQE) of devices 1-4. Among these devices, the device using red dopant 1 exhibited good red emission and efficient EL performance with a maximum luminous efficiency, power efficiency and external quant-

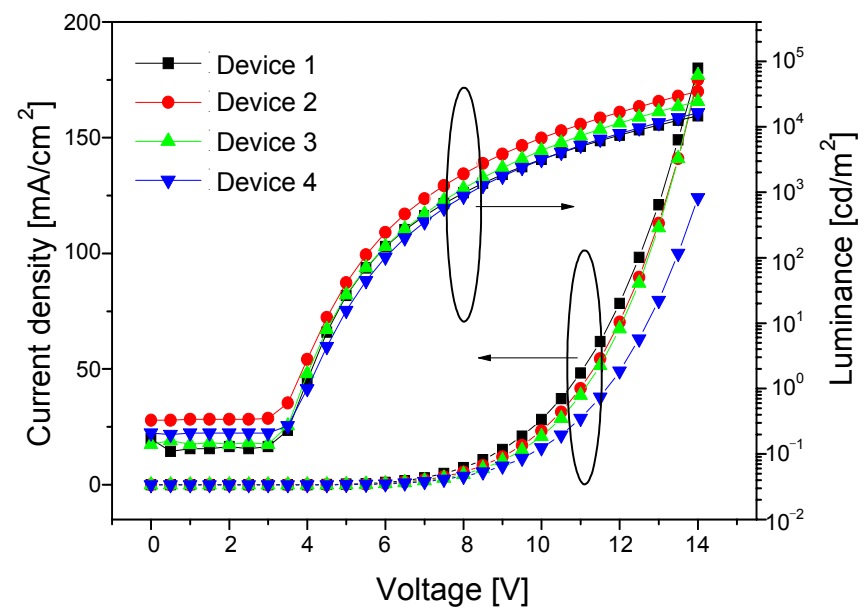

Figure 5. $J-V-L$ curves for OLED the devices 1-4.

um efficiency of $15.6 \mathrm{~cd} / \mathrm{A}, 10.1 \mathrm{~lm} / \mathrm{W}(11.7 \mathrm{~cd} / \mathrm{A}$, and $3.88 \mathrm{~lm} /$ $\mathrm{W}$ at $20 \mathrm{~mA} / \mathrm{cm}^{2}$ ) and $9.58 \%$ at $20 \mathrm{~mA} / \mathrm{cm}^{2}$, respectively. In particular, a change in the fluorine position in the ligands leads to differences in the EL properties of the devices using them as dopants. For example, compared to device $\mathbf{1}$ using complex $\mathbf{1}$, the external quantum efficiency (EQE) of device 2 using complex 2 was decreased by $14 \%$ at $20 \mathrm{~mA} / \mathrm{cm}^{2}$. Compared to device $\mathbf{2}$, the effectiveness of the hole trapping processes in device $\mathbf{1}$ would contribute to this observation. In device 1, the HOMO energy difference between complex $1(-5.68 \mathrm{eV})$ and NPB $(-5.51 \mathrm{eV})$ was $0.17 \mathrm{eV}$. In device 2 , the HOMO energy difference between complex $2(-5.86 \mathrm{eV})$ and NPB $(-5.51 \mathrm{eV})$ was $0.35 \mathrm{eV}$. This suggests that the hole trapping processes are 0.18 $\mathrm{eV}$ more effective in device 1 than device $\mathbf{2}$, which results in an improved EQE of device $\mathbf{1}$ compared to device 2. A similar trend was observed in devices 3 and 4, when the position of the fluorine substitution in the phenyl unit $(2,4-\mathrm{F} \rightarrow 3,5-\mathrm{F})$ in dopant was changed. For example, the same HOMO energy level of complex $4(-5.51 \mathrm{eV})$ as NPB $(-5.51 \mathrm{eV})$ indicates that the hole trapping processes are $0.26 \mathrm{eV}$ more effective in device 4 than device 3 using complex $\mathbf{3}(-5.77 \mathrm{eV})$. Therefore, this difference in the effectiveness of hole trapping processes show that device 4 has a $112 \%$ superior EL efficiency to that of device 3 . However, in devices $\mathbf{2}$ and $\mathbf{3}$, other factors, such as the effectiveness of charge recombination and exciton formation as well as charge balance in the emitting layer, can affect the EL efficiency of the devices because the effectiveness of hole-trapping showed an 
(a)

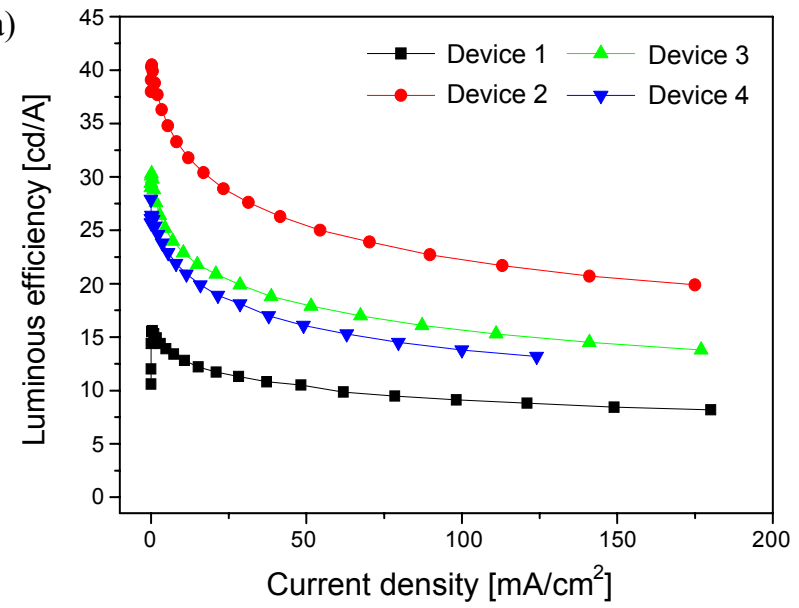

(b)

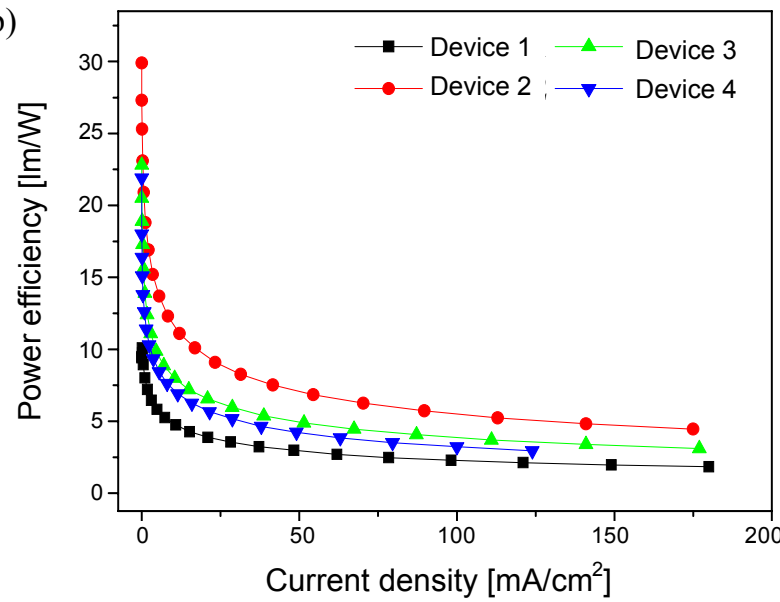

(c)

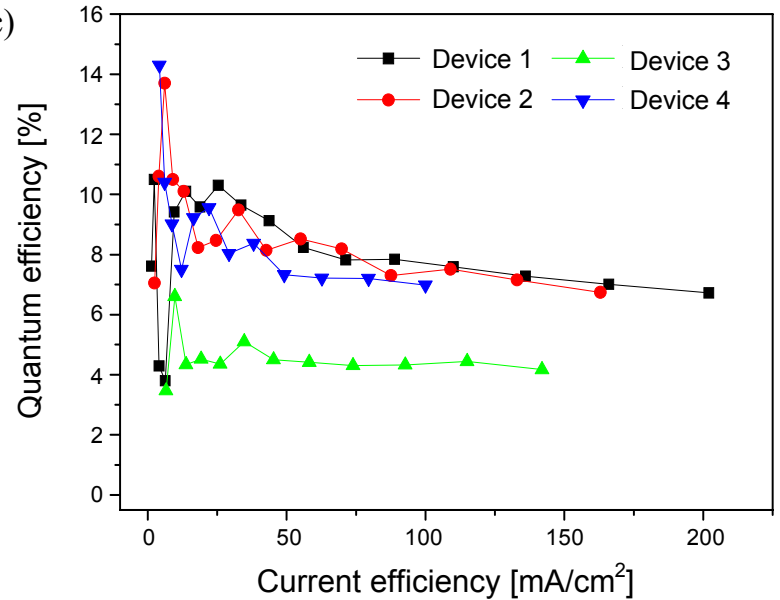

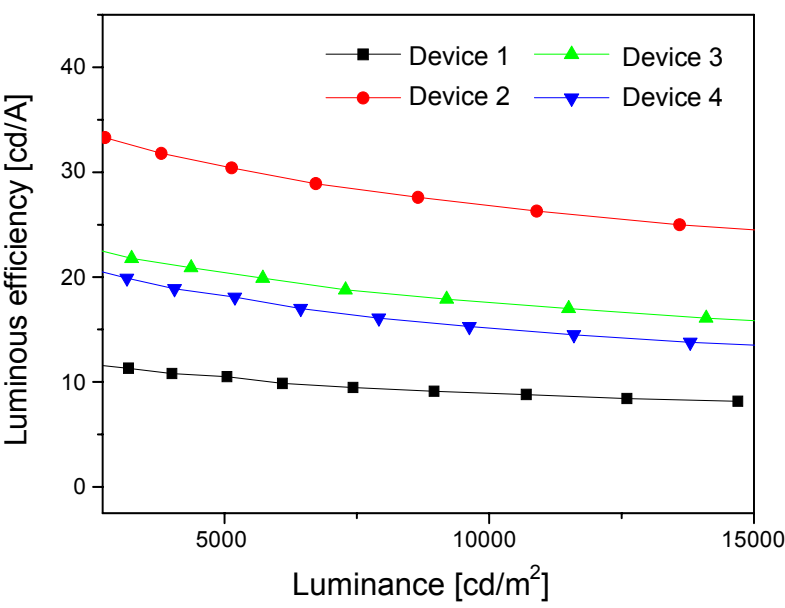
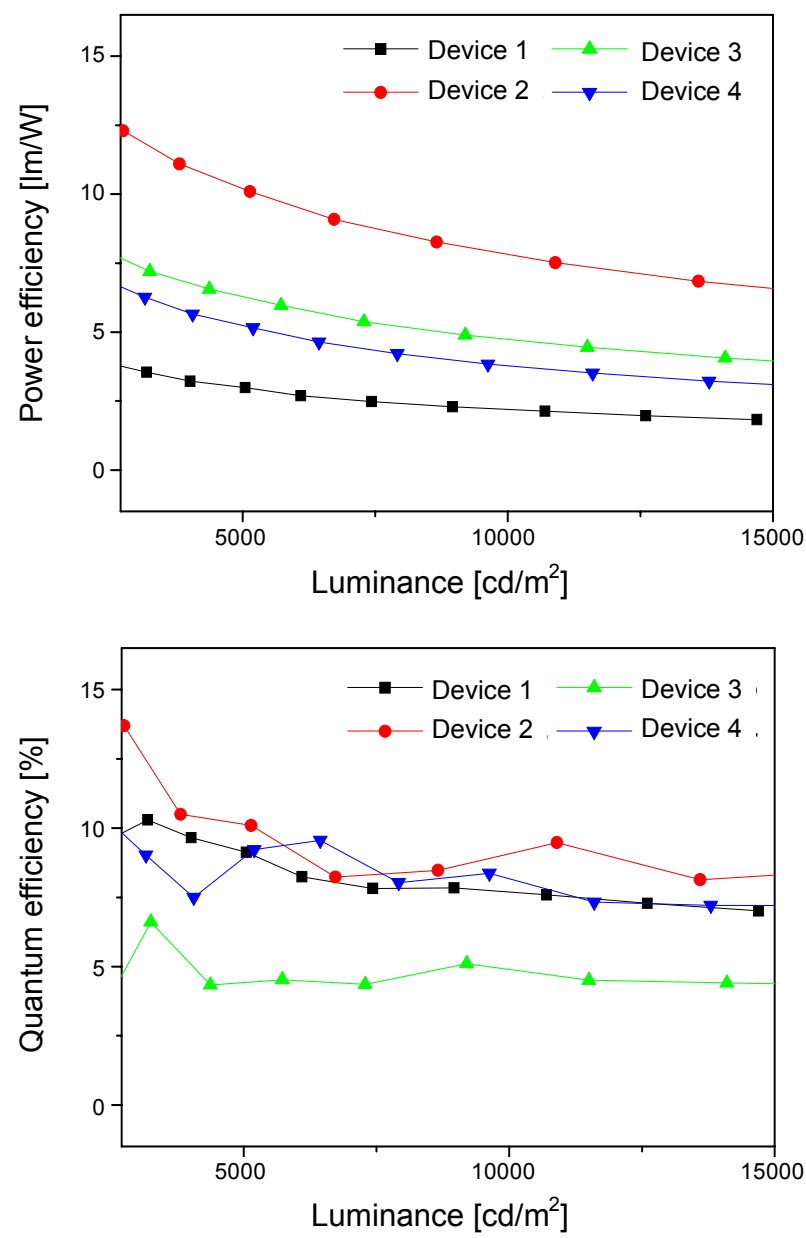

Figure 6. (a) Luminous, (b) power, and (c) external quantum efficiencies of the devices 1-4 as a function of current density (left) and device luminance (right).

opposite trend in the EL efficiencies in devices 2 and $\mathbf{3}$.

Compared to the device using (Bzppy) $\operatorname{Ir}$ (acac) without a fluorine substituents as a dopant, device $\mathbf{1}$ using complex $\mathbf{1}$ with fluorine in the benzoyl unit as a dopant showed improved EL performance. For example, compared to the device using (Bzppy) $)_{2} \operatorname{Ir}(\mathbf{a c a c})$, the external quantum and power efficiency of device 1 increased by approximately 100 and 50\%, respectively. This shows that the fluorine substituent in the ligand of the phosphorescent Ir(III) complexes can help improve the EL performance by tuning the energy levels and charge transporting properties of the emitting materials in the solid state device. Furthermore, this study demonstrated the excellent properties of a red phosphorescent $\operatorname{Ir}(\mathrm{III})$ complex 1 with a 4-fluorinephenyl-benzoyl-2-phenylpyridine ligand for applications to red emitting materials in OLEDs. In particular, this highly efficient red emitting dopant can be used as a phosphorescent red emitter in 
WOLED. Previously, a highly efficient WOLED using (Bzppy) Ir(acac) as a phosphorescent red emitter was reported. This WOLED showed a maximum power efficiency, maximum external quantum efficiency and CIE coordinates of $28.69 \mathrm{~lm} / \mathrm{W}$, $13.1 \%$ and $(0.37,0.37)$, respectively. ${ }^{29}$ Accordingly, the highly efficient red emitting material 1 can be combined with suitable blue $^{30}$ and green ${ }^{31}$ emitting materials to fabricate efficient WOLEDs.

\section{Conclusion}

A series of benzoylphenylpyridine Ir(III) complexes were synthesized and their electroluminescent properties were investigated. The fluorine substituent in the ligand of phosphorescent Ir(III) complexes can help improve the EL performance by tuning the energy levels and hole-trapping processes in the devices for applications as the red emitting materials in OLEDs. A device employing 1 as a dopant exhibited efficient red emission with a maximum luminance, external quantum efficiency and CIE coordinates of $14700 \mathrm{~cd} / \mathrm{m}^{2}$ at $14.0 \mathrm{~V}, 9.58 \%$ at $20 \mathrm{~mA} /$ $\mathrm{cm}^{2}$ and $(0.61,0.39)$ at $12.0 \mathrm{~V}$, respectively. The device also showed stable color chromaticity with various voltages. This highly efficient red emitting material 1 can be used as a phosphorescent red emitter in WOLEDs.

Acknowledgments. This research was supported by Basic Science Research Program through the National Research Foundation of Korea(NRF) funded by the Ministry of Education, Science and Technology(20100007370).

\section{References}

1. Li, C. L.; Su, Y. J.; Tao, Y. T.; Chou, P.-T.; Chien, C. H.; Cheng, C.-C. Adv. Funct. Mater. 2005, 15, 387.

2. Kohler, A.; Wilson, J. S.; Forrest, R. H. Adv. Mater. 2002, 14, 701.

3. D'Andrade, B. W.; Brooks, J.; Admovich, V.; Thompson, M. E.; Forrest, S. R. Adv. Mater. 2002, 14, 1032.

4. Adachi, C.; Baldo, M. A.; Thompson, M. E.; Forrest, S. R. J. Appl. Phys. 2001, 90, 5048.

5. Kawamura, Y.; Goushi, K.; Brooks, J.; Brown, J. J.; Sasabe, H.; Adachi, C. Appl. Phys. Lett. 2005, 86, 071104.

6. Kohler, A.; Wilson, J. S.; Friend, R. H. Adv. Mater. 2002, 14, 701.
7. Chen, F. C.; Yang, Y. Appl. Phys. Lett. 2002, 80, 2308.

8. Ahn, S. Y.; Lee, A. S.; Seo, J. H.; Kim, Y. K.; Ha, Y. Thin Solid Films. 2009, 517, 4111.

9. Lee, S. J.; Park, J. S.; Song, M.; Shin, I. A.; Kim, Y. I.; Lee, J. W.; Kang, J. W.; Gal, Y. S.; Kang, S.; Lee, J. Y.; Jing, S. H.; Kim, H. S.; Chae, M. Y.; Ji, S. H. Adv. Funct. Mater. 2009, 19, 2205.

10. Yang, C.; Zhang, X.; You, H.; Zhu, L.; Chen, L.; Zhu, L.; Tao, Y.; Ma, D.; Shuai, Z.; Qin, J. Adv. Funct. Mater. 2008, 18, 928.

11. Chen, C.-T. Chem. Mater. 2004, 16, 4389.

12. Cummings, S. D.; Eisenberg, R. J. Am. Chem. Soc. 1996, 118 , 1946.

13. Justin Thomas, K. R.; Velusamy, M.; Lin, J. T.; Chein, C.-H.; Tao, Y.-T.; Wen, Y. S.; Hu, Y.-H.; Chou, P. T. Inog. Chem. 2005, 44, 5677.

14. Lo, K. K.-W.; Chung, C.-K.; Zhu, N. Chem. Eur. J. 2003, 9, 475.

15. Lee, K. H.; Kim, J. H.; Seo, J. H.; Kim, Y. K.; Yoon, S. S. J. Nanosci. Nanotechnol. 2010, 10, 3193.

16. Lee, K. H.; Park, J. K.; You, J. N.; Seo, J. H.; Kim, Y. K.; Yoon, S. S. IMID DIGEST 2009, 709.

17. Seo, J. H.; Seo, J. H.; Kim, Y. K.; Hyung, G. W.; Hwang, J. H.; Shin, D. M.; Lee, K. H.; Kwon, Y. S.; Yoon, S. S.; Kim, Y. H.; Kim, W. Y. SID 08 DIGEST 2008, 2025.

18. Hong, H. W.; Chen, T. M. Mater. Chem. Phys. 2007, 101, 170.

19. Wang, Y.; Petrov, V. A.; Grousin, V. V. Pat. Appl (Dupont) 2000.

20. Grushin, V. V.; Herron, N.; Lecloux, D. D.; Marshall, W. J.; Petrov, V. A.; Wang, Y. Chem. Commun. 2001, 1494.

21. Ho, C. L.; Wong, W. Y.; Zhou, G. J.; Xie, Z.; Wang, L. Adv. Funct. Mater. 2007, 17, 2925.

22. Lee, K. H.; Kang, H. J.; Park, J. K.; Seo, J. H.; Kim, Y. K.; Yoon, S. S. Thin Solid Films. 2010, 518, 6188.

23. Lamansky, S.; Djurovich, P.; Murphy, D.; Abdel-Razzaq, F.; Lee, H. E.; Adachi, C.; Burrows, P. E.; Forrest, S. R.; Thompson, M. E. J. Am. Chem. Soc. 2001, 123, 4304.

24. Balton, C. B.; Murtaza, Z.; Shaver, R. J.; Rillema, D. P. Inorg. Chem. 1992, 31, 3230.

25. Colombo, M. G.; Brunold, T. C.; Reidener, T.; Gudel, H. U.; Fortsch, M.; Burgi, H.-B. Inorg. Chem. 1994, 33, 545.

26. Wong, W. Y.; Zhou, G. J.; Yu, X. M.; Kwok, H. S.; Tang, B. Z. Adv. Funct. Mater. 2006, 16, 838.

27. Laskar, I. R.; Chen, T.-M. Chem. Mater. 2004, 16, 111.

28. Yang, C.; Zhang, X.; You, H.; Zhu, L.; Chen, L.; Zhu, L.; Tao, Y.; Ma, D.; Shuai, Z.; Qin, J. Adv. Funct. Mater. 2007, 17, 651.

29. Seo, J. H.; Park, I. H.; Kim, G. Y.; Lee, K. H.; Kim, M. K.; Yoon, S. S.; Kim, Y. K. Appl. Phys. Lett. 2008, 92, 183303.

30. Lee, K. H.; Kang, L. K.; Lee, J. Y.; Kang, S. W.; Jeon, S. O.; Yook, K. S.; Lee, J. Y.; Yoon, S. S. Adv. Funct. Mater. 2010, 20, 1345.

31. Lee, K. H.; Seo, J. H.; Kim, Y. K.; Yoon, S. S. J. Nanosci. Nanotechnol. 2009, 9, 7099. 